\title{
Navigating Internships and Field Experience in the Wake of a Global Pandemic: A Qualitative Examination of Two Undergraduate Program Experiences
}

\author{
Nicola Davis Bivens \\ Johnson C. Smith University \\ 100 Beatties Ford Road Charlotte, North Carolina 28216 USA \\ (704) 330-1481 \\ Yolanda Meade Byrd \\ Winston-Salem State University \\ 601 S. Martin Luther King, Jr. Drive Winston-Salem \\ North Carolina 27110 USA \\ (336)336-750-2085
}

\begin{abstract}
As a result of the 2019 COVID-19 pandemic, approximately 90\% of students across 192 countries, including the United States, were abruptly transitioned from face to face classes to virtual learning due to virus related closures (United Nations Educational, Scientific and Cultural Organization, 2020). While most colleges and universities responded by transitioning all of their face to face courses virtually, that was not a viable or realistic option for students enrolled in for-credit, academic internship and field experience courses given the inherent nature of the courses where students work in a discipline or profession related organization under the supervision of a field supervisor and guided by internship faculty (Davis Bivens, 2011). The following article is a qualitative examination of two social and professional science programs, one in Criminology and the other Social Work, and their experience in successfully transitioning undergraduate internship courses from face to face to virtual courses amid the COVID-19 global pandemic. We make recommendations for faculty supervising internships, field experiences, and other experiential learning activities such as service learning and co-operative education, to anticipate for and prepare for disruptions due to disasters, pandemics, and other critical incidents.
\end{abstract}

Keywords: Internship, field experience, experiential learning, service-learning, critical incidents, COVID-19, disaster planning

Since the first documented internship in Psychology in 1906, internships have become an effective pedagogical tool in just about every academic discipline, including Criminology and Social Work (Davis Bivens, 2011).It is estimated that 1.5 million students complete internships each year (Perlin, 2012). Hart Research Associations (2013) report that $47 \%$ of organizations afford internship opportunities to help promote student success after graduation. There are few opportunities in college courses which afford students the opportunity to develop skill sets expected in the workforce and improve their analytical skills. Internships are an effective way to gain certain competencies not possible in any other setting (Davis Bivens, 2011). These experiential learning opportunities not only benefit students in that they are able to gain invaluable experience in their chosen fields, develop their professional network, but colleges and universities as well. Internships and field experiences connect academic programs to the community. Academic programs can evaluate their curriculums by determining whether the curriculum meets the needs of the workforce and the professional community, and can use employer feedback for program assessment. Faculty are able to determine if their students are adequately prepared for the workforce (Davis Bivens 2011).

Despite all of their promise, extreme circumstances and critical incidents, such as a natural disaster or global pandemic, have the potential to derail the field experience. This article isa qualitative examination of two social and professional science programs, one in Criminology and the other Social Work, and their experience in successfully transitioning undergraduate internship courses from face to face to virtual courses amid the Coronavirus Disease 2019 (COVID-19) global pandemic. We make recommendations for faculty supervising internships, field experiences, and other experiential learning activities such as service learning and co-operative education, to anticipate for and prepare for disruptions due to disasters, pandemics, and other critical incidents.

\section{1 - Critical Incidents and Higher Education}

In the United States, 9 out of 10 persons live in communities at risk of critical incidents such as terror attacks and natural disasters such as earthquakes, floods, and tornadoes (Ripley, 2009). 
According to data from the Emergency Events Database (EM-DAT) at the Centre for Research on the Epidemiology of Disasters (CRED), from January 2015 to June 2020, there were 2,927 natural and technical hazards affecting communities throughout the United States (EM-DAT, 2020).Colleges and universities, embedded within the communities in which they are geographically located, are not "immune" and are subject to the risks and hazards posed by disasters and other critical incidents. In turn, the organizations and facilities where students complete their internships can be impacted by these disasters (Megargee, 2012), including short term and long term closures.

Within the last 50 years alone, colleges and universities in the United States have been subject to natural and technological hazards, including terror attacks which disrupted the semester. In April 1974, Central State and Wilberforce Universities in Ohio were devastated by an F5 tornado (wind speeds greater than $261 \mathrm{MPH}$ ] (Haddow, Bullock, \& Coppola, 2014), which resulted in injuries, fatalities, and extensive property damage and the closure of both campuses. As much as $80 \%$ of the Central State campus was severely damaged, and while Wilberforce had negligible physical damage, it lost infrastructure due to downed power lines and disruptions to water and gas utilities (Prewitt, 1974).In April 2011, Shaw University in North Carolina had a similar experience when an F3 tornado [wind speeds of 158 to $206 \mathrm{MPH}$ ] (Haddow, et al., 2014) touched down in the center of their downtown, urban campus, causing $\$ 3.7$ million in damage and cancelling classes for the remainder of the academic year (WRAL, 2012).

When Hurricane Katrina devastated the Gulf Coast region In August 2005, the world witnessed a "catastrophe, far greater in scale than almost anything in American history" (Solnit, 2009, p. 235). In the city of New Orleans alone, over 600,000 persons were displaced for at least one month as 70\% of all occupied housing units in New Orleans were damaged as a result of flooding caused by the Category Five hurricane (Plyer, 2016), including students enrolled at one of the six universities in the city. These campuses were further impacted by Hurricane Rita the following month (Love, 2008). Southern University's New Orleans campus was underwater, and its students were moved to the University's Baton Rouge campus for the remainder of the fall semester, and reopened in New Orleans in February 2006 with classes, students, etc. housed in Federal Emergency Management Administration (FEMA) trailers and temporary structures (Southern University New Orleans, n.d.).Dillard University, adjacent to some of the failed levees in the city, was under seven feet of water, and two residence halls burned as a result of fires caused by ruptured gas lines. Students were displaced, enrolling at colleges and universities throughout the country willing to accept them. In January 2006, the university reopened in rented space at the Hilton Hotel, with classes offered in the ball rooms, meeting spaces, etc. and students, as well as some faculty and staff, living in the hotel accommodations (Love, 2008).

\section{2 - Global Pandemics and Higher Education}

While higher education has long been impacted by natural disasters as previously described, global pandemics are rare occurrences. In fact, prior toCOVID-19, there had only been four pandemics which have impacted the United States; the 1918 Spanish Influenza, 1957-1958 Asian Flu (H2N2), and the 1968 Hong Kong Flu [H3N2] (Centers for Disease Control and Prevention, 2020).These pandemics impacted the faculty, staff, students, and disrupted the normal course of the semester. For example, like countless other universities across the country, Elon College (the predecessor for modern-day Elon University) in North Carolina, was impacted by the 1918 Influenza. As then president of the college, William Allen Harper, noted, "within a matter of days, almost of hours, the college was in the grip of an emergency that threatened far more destruction to the community than the war overseas...." (Stokes, as cited in Brown, 2020). Influenza was rampant throughout the campus community as three out of four Elon students got the flu (which claimed the lives of three students), with faculty becoming sick as well. While the college never officially cancelled during the pandemic, classes failed to meet once faculty and students were too sick to attend (Brown, 2020).

Whereas natural and technological hazards, as well as acts of terror, only impact limited geographical areas, pandemics have far reaching implications as evidenced by the 2019 COVID-19 pandemic. Colleges and universities around the globe had to rapidly respond to an ever changing hazards cape. According to The United Nations Educational, Scientific and Cultural Organization [UNESCO] (2020), approximately 90\% of students across 192 countries, including the United States, were transitioned online as a result of COVID-19 related closures as of June 4, 2020.Most universities responded by transitioning all of their face to face courses virtually, as either online courses using learning management software such as Canvas, Moodle, etc.; virtual meeting spaces such as Zoom or Microsoft Teams; or some other type of distance based learning, such as emailing work to the professor or watching recorded lectures uploaded to YouTube (Muthuprasad, Aiswarya, Aditya \& Jha, 2020).Students generally found the abrupt transition from face to face classes to virtual learning favorable in that it met their learning needs, (Agarwal \& Kaushik, 2020), kept them engaged in the class (Carrillo, 2020), improved their technical skills, as well as helped them with their comprehension skills (Muthuprasad, et al., 2020). 


\section{3 - Internships and Field Experience Amid the COVID-19 Pandemic}

While most courses were able to be successfully moved to remote learning, transitioning online was not a viable or realistic option for students enrolled in for-credit, academic internships given the inherent nature of internships and field experiences, where students work on-site in a discipline or profession related organization under the supervision of a field supervisor and guided by internship faculty (Davis Bivens, 2011).For both universities in this examination, the transition to move online was mid-point in a standard 16 week semester, with both schools going online on or before March 30, 2020.At that point, approximately 22.5 million persons nationwide were displaced from work due to closures, furloughs, etc. as a result of COVID-19 (Bureau of Labor Statistics, as cited in Ettlinger\& Hensley, 2020), including many of the students' local internship placements.In addition, the dormitories were closed, with students having up to 14 days to move off campus no later than March 30, 2020.For those placement sites still open, they were either 1) working remotely due to shelter in place provisions, or 2) not allowing the interns to work on-site due to COVID-19 safety protocols, and thus working on-site in the agency was no longer an option for students. Of the students who lived on campus, many were from communities at least 100 miles from campus, and commuting back to the city was not an option in the event their agency placement was still open. Most if not all, of the displaced students did not have a local housing option (i.e. staying with friends or family) to allow them to remain in the vicinity to allow them to complete the balance of their required internship hours.

Working closely with agency supervisors, internship/field faculty worked to develop real and meaningful activities. In Criminology, one internship placement simply wanted to allow students to read their policy and procedures manual and case files to get a better understanding of the same. However, faculty had to explain that was not a suitable assignment as there was not any way to assess whether students had learned or could demonstrate a mastery of the skills tied to the same. However, the agencies, in conjunction with internship faculty were able to come to consensus on meaningful assignments and projects that students could complete remotely. In one agency, the use of Zoom allowed the staff and intern to continue to work with their population as meetings and sessions were now occurring remotely vs. in the office.

As a result of concerns of student well-being based the level of susceptibility to the virus based on published advisories from the Centers for Disease Control and Prevention, and student demographics (i.e. African American, ages 20-65), the Social Work department chair, with special approval from upper administration, removed all Social Work majors from on-site, internship placements in the region. Faculty, working closely with the director of field education, developed alternative remote internships for each student. These remote placements were done in consult with agency staff to determine the agency's capacity to assign remote learning activities to the assigned students. Although most of the phone calls were met with favorable ideas and outcomes, some field instructors struggled with developing appropriate activities. Another challenge was that agency databases and client delivery systems were not externally accessible by the student, and these agencies experienced the most difficulty in assigning activities.

Throughout the course of a "normal" field placement, faculty maintain ongoing contact with the placement agencies. to inquire about the students' performance in the agency. Once the placements were remote, agency contacts were not only inquiries about student performance, but they seemingly became "wellness checks," about the welfare of the field instructor, clients, and agency.

\section{4 - Evaluation and Assessment of the Internship and Field Placements Amid COVID-19}

The following discussion of the student, faculty, and field supervisors' experiences is based on multiple sources of qualitative assessments, based on 1) content analysis of student reflective journals, 2) feedback and observations collected during meetings and contact with students and field supervisors, and 3) discussions among internship and field placement faculty.

\subsection{Student Observations}

For the Criminology internship, students are required to document and reflect on their experiences through journaling. Journaling is an accepted pedagogy which also allows studentsto develop writing skills and facilitate critical thought (Walker, 2006). Students are required to submit journals three times in the course of the semester. That journaling allows the internship faculty to assess student learning, their ability to reflect on their learning experience, and demonstrate their ability to bridge theory and practice. For both Criminology and Social Work, Students were also required to maintain their classroom contact hours weekly, meeting synchronously via Zoom, which served as part of the evaluation and assessment process.During these sessions, students also shared their experiences and reflections about their field experiences. A content analysis of the journal entries collected after the university transitioned to remote learning and feedback, discussions well as reflections shared during the synchronous sessions, and reflection on the curriculum redesign process to transition online revealed the following recurring themes: 
- Overall, students were extremely resilient in the disruption to their academic experience.However, in those instances where agencies were unable to continue to offer interns any type of experience, said students displayed high levels of anxiety and expressed concern they would not complete the required hours by the end of the semester. In Social Work, student journal entries reflected the frustration felt because of having to be changed to a different placement.

- While they had initial concerns as to whether they would be able to complete the balance of their hours and successfully complete the course, they were appreciative that the agency supervisors and staff created learning opportunities and assignments. In turn, they were glad for the opportunity to have the semester long internship and it not be cut short as a result of the closures, etc.

- $\quad$ Students enjoyed the autonomy of working remotely and the ability to make some independent judgments, providing a greater confidence in their decision-making and opportunity to apply their knowledge, skills and abilities in the workplace.

- Students, reliant on campus based technology, were now disadvantaged as they did not have these resources once they returned to their home communities. One student not did not have a laptop to use at home to complete assignments. Another, living in a rural area, did not have reliable Internet. Another student reported having to share a laptop with her mother (who was now working from home during the day as a result of statewide shelter in place mandates).

- Despite their own displacement, students still desired meaningful learning opportunities which would allow them to gain and demonstrate their competencies. Several of the students assigned remote internships reported being "under-tasked" and requested to be reassigned to either a different, or additional placement where they could complete the needed remaining hours and demonstrate the competencies required for the profession. Seniors were very concerned about the assignment of meaningful activities to aid in developing the skillsets needed to be a competent Social Work professional.

- Traditionally, "school" and "home" were two very distinct spaces for students, each providing a different sense of place. According to Holton (2015), students have different expectations of "home" and "university" as it pertains to their security and identity. Students shared being "home" during summer, spring, and winter breaks, etc. as a place of "rest" and a respite from the demands of college. Those students who had to move back to their respective communities were now struggling with their home space now also serving as their school space and the places were now coterminous. Students shared that they lacked privacy and were unable to concentrate and focus on classwork and their internship responsibilities. They were now required to help their parents with caring for children and dependent adults within the home. There was financial stress, as most of the students in the program were no longer able to work their part-time jobs as a result of returning home. Students who were once independent now were once again dependent on parents, who they themselves, were struggling financially to make ends meet.

- Students appreciated the synchronous, live sessions as it gave them a sense of normalcy and structure.According to one student, "because the class was live, I am able to use it as an excuse to have 'alone time' away from everyone else (especially my younger siblings) in the house."

- $\quad$ One of the students' remote placement was that she facilitated several live fitness sessions via Zoom and created public service announcements about COVID-19 using Adobe Spark. This learner shared she felt the new tasks utilized her strengths and allowed her to exercise some control over her academic experience and COVID-19. She was "excited to do something productive to help faculty and students better cope during such a difficult time."

- A number of students shared that they gained a confidence in their ability to adapt to change and in their ability to succeed. As one student noted:

As a Millennial or whatever I am, my classmates/generation and I are criticized for being sheltered and unable to handle stress.Being able to finish this internship, this semester of college, and graduate from college shows that I a tougher than given credit for.Now when I get to a job interview and they ask me a question like 'when have I overcome adversity or a barrier or something like that', I can proudly say that I was able to survive having my last semester of college interrupted by a virus and still graduate on time.

\subsection{Faculty Observations}

The first COVID-19 case in North Carolina was diagnosed on March 3, 2020. Just one week later, on March 10, the state's governor declared a state of emergency (Cooper, 2002).Within days of that declaration, universities across the state, began sending students home and transitioning their courses online. As such, important, impactful decisions about field placement and internships had to be made almost instantaneously. There was not any guidance, critical incident debriefing, white paper, or anything to provide perspective on how to best handle this transition. Faculty sought guidance from peers and colleagues in other disciplines, both on campus and at other universities, and they were as perplexed and unprepared to transition the internship courses. Existing literature about internships, continuity in the wake of disasters, etc. did not provide any insight or contribution to help manage the transition. 
As one internship faculty member noted,

I was woefully unprepared for the interruption. While I take great pride in a thorough and detailed internship syllabus/manual, with policies and guidelines for every foreseeable event (or so I thought), despite having a background in public safety and emergency management, I failed to plan for a critical incident like a natural or technological disaster, let alone a global pandemic.

COVID-19 is unprecedented in that it was not a short term interruption, or isolated to one geographic location (like hurricanes or tornadoes), but it impacted millions of students from kindergarten to post- secondary education world-wide.One faculty member, who, as an undergraduate student, was temporarily displaced by Hurricane Hugo in 1989, when classes were cancelled, students were told to vacate the dorms, etc. for approximately one week, but nothing experienced, as a student or faculty member prepared us for the pandemic and how tosuccessfully manage and transition the internship course to a remote, distance based experience. The students are truly to be commended for their ability and maturity (much greater than expected) to handle such an unprecedented disruption in the wake of uncertainty.They not only had their semester interrupted (and in some cases, their final semester of college and the rituals of spring break, senior week, baccalaureate services, commencement, etc), but in a matter of weeks, they were moving out of dorms, returning home, and transitioning to being online students, all the while, still completing an internship placement remotely.

Agency supervisors have long been viewed as partners in experiential learning opportunities (Davis Bivens, 2011), but their overwhelming willingness to allow the students to continue to intern, and come up with suitable assignments, supervise the intern, etc. is commendable. Given that these supervisors, they themselves, were dealing with transitions in their own organizations due to closures, working remotely, etc. and navigating a "new normal" and faced with working from home, homeschooling their own children, etc. Their commitment to preparing the next generation of Criminology and Social Work professionals was unwavering and demonstrated in their service to students. Agency supervisors were learning to master Zoom and similar platforms to not only meet with students, but conduct their own work, etc. In one instance, because the student had to deliver hard copies of files, etc. to her agency placement, the intern and agency supervisor met in person, separated by a glass storm door, with the student on the porch, the supervisor inside, and they spoke on the phone.

Some agency supervisors were overwhelmed and did not have some of the tools and information needed to work virtually and complete routine tasks such as signing documents with a digital signature or scanning documents. Faculty provided students and supervisors with information about the use of various applications such as Docusign and software such as Adobe to be able to complete these tasks.

Approximately $70 \%$ of the Social Work students were able to remain in their original placements and work remotely. These students seemingly experienced the least amount of disruption and transitioned well with online learning and remote internship. Supervisors in these agencies often had agency databases that the student could access from home. These agencies also were innovative in their approach to learning activities and tasks.

Based on feedback from agency staff, students, and review of the students' journals, those students who were shared between two agencies/supervisors experienced role confusion, ambiguity and stress.

\subsection{Agency Supervisor Observations}

- Students are extremely tech-savvy. As a result, one agency supervisor reported that the student's knowledge of certain applications, software, and various platforms greatly benefited the organization as it transitioned online. Students also helped staff learn the technology, which once adopted, helped increase productivity and allowed the organization to continue to serve its clients.

- One field instructor advised that she was concerned that she may no longer have a job as she could no longer service her clients. Social Work faculty worked with the supervisor to develop sessions with clients via Zoom, thereby allowing her to service her clients.

- $\quad$ Communication, while always essential, was needed all the more when working with students remotely. One field supervisor indicated the need to be flexible in communicating with the interns, including Zoom, phone calls, and text messages (which was the preferred method of the students).

\section{5 - Lessons Learned and Recommendations for the Future}

Focusing events force attention on problems and developing solutions to said problems (Kingdon, as cited in Birkland \& Warnement, 2015).Critical incidents, such as disasters, catastrophes, and crises, can impact policy and can serve as a focusing event (Birkland \& Warnement, 2015). There is little question, that Hurricane Katrina is a focusing event (Birkland, 2006) and it is certain that COVID 19 will be as well. As universities are still busy planning for the next academic year, and the uncertainty in response to COVID-19 and preparing for the next disaster or critical incident, the following recommendations are made. 
These can be adapted in any type of experiential learning setting, not just internship and field experience courses, but service learning and co-op experiences as well.

\section{1 - Seek Guidance from Professional Organizations and Accrediting Agencies}

Internships and field experiences are often guided by, or must adhere to minimum standards, expectations outlined by professional organizations or accrediting bodies. Refer to the requirements and recommendations outlined by those organizations. For example, in the wake of COVID-19, the Council on Social Work Education (CSWE) provided guidance on the use of field seminar and professional development activities (both real and simulated) that could be used to help students fulfill the hours required for field placement. CSWE also decreased the number of required hours. However, the Social Work program opted not to reduce the hours of students as they were needed for the interns to be able to assume tasks needed to demonstrate competencies.

Even if the academic discipline or coordinating professional organization does not provide that type of guidance, as is the case with the Academy of Criminal Justice Sciences (ACJS, 2018), look to other related disciplines which may. For example, the American Psychological Association Commission on Accreditation provided guidance to academic programs on dealing with the loss of placement or inability to complete the prescribed number of field hours in the wake of COVID-19 (APA, 2020).

Faculty should also refer to guidelines and requirements from their respective regional accrediting bodies, such as the Southern Association of Colleges and Schools Commission on Colleges or the Middle States Commission on Higher Education, to determine what, if any, standards must be adhered to or if there is guidance on how to transition experiential learning opportunities, etc.

\section{2 - Identify Alternative Methods to Assess and Evaluate Student Learning and Performance}

Internship and field placement can serve as a means of assessment of student learning, program outcomes, as well as to determine if the curriculum meets the needs of the workforce and the professional community (Davis Bivens, 2011). Criminology students would often have a previously agreed upon project, service or deliverable they had to provide the internship placement, and in-person site visits are performed to assess student performance in the internship placement. Closures no longer allowed for faculty to perform on-site assessments, and changes to projects, services, or deliverables required that faculty identify alternative methods to assess and evaluate student learning and performance. For example, one student completing her internship in a private law firm, was given an "alternative" assignment of assembling and organizing discovery files, etc. Given the attorney-client privilege, faculty no longer could measure or evaluate their "performance" in their ability to create the files due to the confidentiality of those files. As a result, the agency supervisor's assessment and observation of the student's ability was given greater "weight" in assessing student learning in this instance.

Under normal circumstances, students are evaluated by agency faculty, however, because of the pandemic, two social work faculty were also serving as primary field instructors. As a result, the social work faculty participated in the evaluation of those students placed under their field supervision. Evaluation was based on student performance at the "pre-COVID-19 placement" as well as the newly assigned remote learning tasks.

\section{3 - Develop an Orientation for Remote or Virtual Placements}

Soon after the transition to remote placements, Social Work faculty realized that agency supervisors were struggling with the use of technology as well as the development of innovative strategies to reach the clients the agency served based on the feedback received when they made contract throughout the remote/distance based internship. As a result, it was determined that the field supervisors needed an orientation to introduce the concept of "remote internships." As a result, the department chair developed a virtual orientation, delivered via Zoom, for students and agency supervisors, introducing them to the concept of remote internships.

\section{4 - Structured, Yet Flexible Policies and Placements}

Structured internships are more preferable in that they maximize the benefits for students, foster career growth, and link institutions of higher education to the professional community (Davis Bivens, 2011).However, in the wake of a critical incident, the internship policies should be flexible to accommodate changes. For example, the internship policy for Criminology maintains that all of the students' placement hours are completed in one agency, and should the student be terminated from or choose to leave an agency, they cannot "transfer" their worked hours to a subsequent internship or be reassigned to another agency. However, because of the abrupt interruption of the semester, students were given greater flexibility to complete their hours by serving in two agencies, and leniency in receiving an incomplete. For example, one student was unable to secure a placement once she returned to her home community, yet her agency, given the type of placement, was unable to allow her to work remotely. As such, she was assigned an incomplete grade and will have several weeks into the following semester to complete the balance of her hours or seek alternative placement once agencies begin to reopen. Consider on-campus placements, where students can complete hours, demonstrate their competencies, and gain experience. 
For example, students were assigned to the universities' counseling center, within the academic department, and the campus judicial affairs office.

\section{5 - Knowledge of Legal and Ethical Requirements}

Legal requirements and liability issues involved in internship placement must be taken under consideration. Internship and field experience faculty must review legal requirements, such as the Fair Labor Standards Act, EEOC, American with Disabilities Act, and Title VII of the Civil Rights Act, and other legislation which may prove to be a liability matter to the institution (Davis Bivens, 2011).Waivers should be updated to incorporate changes as necessary as a result of COVID-19. It is also recommended that faculty meet with their university's risk management staff or office of legal counsel to make certain that liability insurance covers illness or other consequences as a result of COVID-19 exposure or illness, or injury, displacement, etc. as a result of a natural or technological disaster. In turn, students should be required to sign an acknowledgement of risk, and that they understand that by completing an internship, they may face some risks.

The United States Department of Education has a number of regulations and requirements regarding student matriculation, full time enrollment, etc. In those instances where students were unable to complete their internship as a result of COVID-19 closures, etc., withdrawing from, or taking an incomplete in the course, may impact their full time student status, adequate yearly progress, etc. and thus their eligibility to receive Federal Financial Aid. In the wake of the COIV-19 pandemic, the Department of Education provided guidance on compliance with requirements with Title IV, the Higher Education Act, etc., including interruptions of internships, field work, student teaching, etc. (United States Department of Education, 2020). Faculty should refer to those regulations and guidance's to ensure that students are not negatively impacted by losing their eligibility for aid and that institution are not in jeopardy of non-compliance with the law.

Faculty should also be mindful of ethical considerations. Not only are students required to abide by the code of ethics for their respective disciplines as it pertains to their internship placement (Davis Bivens, 2011), but said ethical standards may dictate the students' relationship to the field agency, clientele, etc. and their ability to continue the placement, etc. as a result of a critical incident. The codes of ethics regarding the field placement supervisor or internship agency itself must also be considered and factored into any decision making. In the absence of having a discipline or profession specific code of ethics, faculty decisions regarding how to navigate changes to the internship placement in response to a disaster or critical incident should be ethical in making their decision.

\section{6 - Threat and Hazard Identification and Risk Assessment - Plan for the Worse}

Recognizing that preparedness is the shared responsibility of the entire nation, then-President Barack Obama signed Presidential Policy Directive 8 on March 30, 2011 requiring individual citizens, communities, faith based organizations, private and non-profit sectors, tribal governments, the national and subnational governments, to contribute to said preparedness for disasters and emergencies (Brown, 2011). The National Preparedness Goal is "a secure and resilient nation with the capabilities required across the whole community to prevent, protect against, mitigate, respond to, and recover from the threats and hazards that pose the greatest risk" (United States Department of Homeland Security, 2015). One of the ways that communities identify and prepare for those threats and hazards is a Threat and Hazard Risk Assessment (THIRA), which allows them to determine 1) the risks and hazards that they must prepare for, 2) the level of capability to be prepared, 3) current capabilities, 4) the gap between the needed level of capability and current capabilities, and 5) how to address said gap. Communities complete THIRAs every three years and should be available allowing the greatest number of community partners to readily access the information (United States Department of Homeland Security, 2018). Faculty should determine if their campus-based or local emergency manager or public safety director has access to the THIRA and assess the campus' vulnerability, and take that into consideration when planning for internships and field experience and possible interruptions to the same. This information should also be shared with students so that they can be cognizant and aware of said risks and anticipate the same. A knowledge and awareness of possible threats will allow faculty to adequately prepare for and mitigate against disasters and critical incidents, and plan accordingly.

\section{7 - Properly Vetting Internship Placements}

In addition to vetting students' internship placements for their suitability to not only provide students with meaningful learning experiences and compliance with any accreditation, certification, or university requirements, faculty should begin to evaluate an organization's ability to remain open and work with an intern in the wake of a critical incident. Does the agency have the appropriate resources to allow interns to continue their placement remotely? Are interns considered essential personnel as it pertains to continuing to work and access a facility, office, etc.? Does the agency have the human capital and resources to effectively supervise and provide meaningful learning experiences remotely? Does the internship agency have the potential for high risk vulnerability, particularly for disease, such as a correctional facility or residential group home? 
For example, one of the internship agencies for the Spring 2020 semester was a non-profit organization, with two staff members, and one was battling terminal illness. When COVID-19 prompted shelter-in-place requirements ordered by the governor, the agency shuttered its doors completely, and the student's internship was essentially eliminated.

\subsection{Require Students Have Laptops with Specific Software and Applications and Capabilities}

As described above, students reliant on university technology were disadvantaged once they returned to their home communities due to not having laptops, etc. in the home, or having to share one device among multiple family members; unreliable (if any) Internet, etc. As a result, students should be required to have devices with specific applications, software, and capabilities they will need to be successful as a remote learner. For example, devices should have processors, memory, etc. to handle certain software, applications, etc. to handle not only basic word processing, etc. but Zoom (or other similar virtual meeting spaces), cameras (to be visible in live sessions, the ability to sign documents remotely, etc. Faculty should also research low cost and free Internet access resources, such as wi-fi hot spots, discounted Internet service providers, etc.

\section{6-Conclusion}

As with any qualitative research, our experiences cannot be generalized beyond the two programs described here. However, given the perspectives and information revealed through our qualitative analysis, we are confident that this information serves as a foundation for which future research, policy, and pedagogy can build upon. We recommend that a quantitative or mixed methods study of other programs and disciplines be conducted to determine how COVID-19 impacted field placements, etc. and how student learning was impacted by the same that can be generalized beyond our two campuses.

Mileti (1999, p. 187) posits that "the nation needs to acknowledge that it will never be totally safe from disasters..." We recognize that the COVID-19 global pandemic serves as a focusing event that allows faculty to reimagine experiential learning and make changes to existing policy, practice, and pedagogy to ensure students successfully complete their learning experiences. These recommendations should serve as a guide for anyone supervising experiential learning opportunities to plan for critical incidents, and still preserve the academic integrity and rigor of the field placement, and continue to promote student success and engagement.

\section{References}

Academy of Criminal Justice Sciences (2018, August 28). Standards for college/university criminal justice/criminology undergraduate baccalaureate degree programs. ACJS.

https://www.acjs.org/page/ProgramStandards

Agarwal, S. \& Kaushik, J.S. (2020). Students' perception of online learning during COVID Pandemic. The Indian Journal of Pediatrics, 87, 554. https://doi.org/10.1007/s12098-020-03327-7

American Psychological Association (2020, March 23). COVID-19: Updates and information.APA. https://www.accreditation.apa.org/covid-19\#intern-postdoc

Birkland, T.A. \&Warnement, M.K. (2015). Focusing events in disasters and development. In N. Kapucu\& K.T. Liou (Eds.). Disaster and development: Examining global issues and cases (39-60). Springer International Publishing

Brown, R. (2020, March 24). The Spanish Flu of 1918 at Elon: 'We did not know what it was,

until we were all sick.' Elon University. https://www.elon.edu/u/news/2020/03/24/weve-been-here-before-elonthe-spanish-flu-of-1918/

Carrillo, A.M. P. (2020). The utility of online resources in times of COVID-19: A Mexican medical student point of view. International Journal of Medical Students, 8 (1), 58-59. 10.5195/ijms.20 Centers for Disease Control and Prevention (2018, August 10). Past pandemics. Centers for Disease Control and Prevention. https://www.cdc.gov/flu/pandemic-resources/basics/past-pandemics.html

Cooper, R. (2020, March 10). Executive Order No. 116. North Carolina Government. https://www.nc.gov/covid19/covid-19-executive-orders

Davis Bivens, N. (2011). Tried and true: Internships as an effective pedagogical criminal justice resource. Journal of Justice Studies 2(1), 4-11.

Emergency Events Database (2020, June 26, 2020). EM-DAT database. Centre for Research on the Epidemiology of Disasters. https://public.emdat.be/data

Ettlinger, M. \& Hensley, J. (2020, June 19). COVID-19 economic crisis: By state. University of

New Hampshire Carsey School of Public Policy. https://carsey.unh.edu/COVID-19-Economic-Impact-By-State

Gault, J., Redington, J. \& Schlager, T. (2000). Undergraduate business internships and career success: Are they related? Journal of Marketing Education, 22(1), 45-54. doi: 52570405

Haddow, G.D.; Bullock, J.A. \& Coppola, D.P. (2014). Introduction to emergency management (5th ed.). Elsevier

Hart Research Associates (2013). It takes more than a major: Employer priorities for college learning and student success. Liberal Education, 99(2). 22-29. 
Holton, M. (2015). Adapting relationships with place: Investigating the evolving place attachment and 'sense of place' of UK higher education students during a period of intense transition. Geoforum, 59, 21-29.

Love, G.C. (2008). A Katrina recovery initiative: Dillard University student projects, January-July 2006. The Journal of African American History, 93(3), 402-209. https://doi.org/10.1086/JAAHv93n3p402

Megargee, E.I. (2012). Megargee's guide to obtaining a Psychology internship. Taylor \& Francis.

Mileti, D.S. (1999). Disasters by design: A reassessment of natural hazards in the United States. Joseph Henry Press

Muthuprasad, T. Aiswarya, S., Aditya, K.S. \& Jha, G.K. (2020). Students' perception and preference for online education in India during COVID -19 Pandemic. Social Sciences \& Humanities Open. http://dx.doi.org/10.2139/ssrn.3596056

Perlin, R. (2012). Intern nation. How to earn nothing and learn little in the brave new economy.Verso

Plyer, A. (2016, August 26). Facts for features: Katrina impact. The Data Center. http://www.datacenterresearch.org/data-resources/katrina/facts-for-impact/

Prewitt, M. (1974, April 9). Tornado levels Central State. Daily Kent Stater, pp.13

Ripley, A. (2009). The unthinkable: Who survives when disaster strikes - and why. Harmony Books Crown Publishing

Solnit, R. (2009). A paradise built in hell: The extraordinary communities that arise in disasters. Viking

Southern University New Orleans (n.d.). SUNO past, present \& future. SUNO. http://www.suno.edu/page/sunopast-present-future

United Nations Educational, Scientific and Cultural Organization (2020, June 25). COVID-19 Impact on education. UNESCO. https://en.unesco.org/covid19/educationresponse

United States Department of Education ( 2020, June 16). Guidance for interruptions of study related to Coronavirus(COVID-

19).USDOE.https://ifap.ed.gov/electronicannouncements/030520Guidance4interruptionsrelated2Coronavir usCOVID19

United States Department of Homeland Security (2018). Threat and Hazard Identification and Risk Assessment (THIRA) and Stakeholder Preparedness Review guide (SPR) ( $3^{\text {rd }}$ ed.).United States Department of Homeland Security

Walker, S.E. (2006). Journal writing as a teaching technique to promote reflection. Journal of Athletic Training, 41(2), 216-221.

WRAL (2012, April 16). Tornado-stricken Shaw University celebrates recovery.

WRAL.https://www.wral.com/news/local/story/10986652/ 